\title{
Crise da cultura? ${ }^{1}$
}

José Luís Jobim

Recebido em 18 jun 2012. Aprovado em 15 ago 2012

\section{Resumo}

Neste artigo, depois de apresentar algumas das perspectivas referentes à associação contemporânea entre cultura e crise, examinaremos as questões da exceção cultural, da diversidade de expressões culturais, da filiação nacional e da globalização, procurando ressaltar a pluralidade das perspectivas envolvidas.

Palavras-chave: cultura; crise 
Hoje em dia vemos muitas matérias em jornais, títulos de livros, artigos em periódicos e magazines que usam a palavra crise: "crise financeira", "crise política", "crise moral", "crise existencial", "crise da representação", "crise do livro", "crise da educação" etc. Quando começamos a ler estes textos, frequentemente nos damos conta de que são narrativas em que se projetam imagens de uma estabilidade antes existente, seguida por uma decadência ou fim de alguma coisa. Em outras palavras, presume-se que algo estável (o mundo das finanças, a política, a moral, a existência humana, o livro...) perde esta condição ou tem esta condição colocada em xeque: é a crise... A crise é apresentada, então, como um problema, sem que se argumente que há também um problema nestas narrativas. Qual?

Bem, muitas vezes a presumida "estabilidade" que existiria antes e que supostamente é ameaçada na crise é apenas uma idealização que nunca correspondeu a uma realidade material efetiva. Claro, a partir dessa idealização, pode-se criticar o que se presume ser uma ameaça, decadência ou fim; mas a crítica é feita em relação ao que foi idealizado anteriormente.

Quanto à palavra cultura, sabemos que é derivada de um verbo que em latim significava cultivar algo, tratar bem de alguma coisa, habitar, cultuar, cuidar. Se desde o Renascimento usamos tanto esta palavra quanto outras formadas a partir dela, é importante ressaltar que ela sempre teve uma direção de sentido que aponta para uma ação ou processo, bem como para o efeito de ações ou processos. Assim, mesmo quando cultura transformou-se em termo técnico na Antropologia, designando um conjunto de costumes, conhecimentos, práticas comportamentais e crenças de uma determinada comunidade humana, a direção de sentido antes mencionada permanece, pois não se considera a cultura de uma comunidade como uma estrutura estática. Também, a partir principalmente do século XVIII no Ocidente, o termo cultura passa a relacionar-se mais estreitamente com a esfera das Belas Artes, e com uma ideia de conhecimento das obras mais relevantes produzidas pela humanidade na literatura, pintura, música, escultura etc.

Quanto ao termo crise, sabemos que atualmente designa também uma situação que é ou pode vir a ser instável ou perigosa para um indivíduo ou uma sociedade, mas quero lembrar aqui que este termo vem de um verbo grego que significava distinguir, escolher, decidir, julgar, entre outros sentidos. Se estas ações enumeradas indicam um papel ativo nas sociedades em que se praticam, no caso da expressão crise da cultura, o termo crise pode designar hoje uma necessidade de alterar a imagem anterior do passado, sintetizada no termo cultura, em função das necessidades e desejos de hoje, nas sociedades ocidentais que o utilizam.

Por outro lado, apresentar o termo cultura como uma herança consolidada, como um modo de ser e estar no mundo correspon- 
dente a uma determinada sociedade no passado pode também ser uma estratégia útil para influenciar decisões políticas no presente e no futuro (WEIL, 1991, p. 216).

Meu argumento, nas linhas que seguem, será, basicamente, que a expressão crise da cultura, hoje, enfatiza a ação de distinguir, escolher, decidir, julgar as manifestações culturais.

Como estas manifestações não ocorrem no espaço sideral, mas em contextos sociais, históricos e econômicos específicos, é importante sempre levar em consideração o ambiente em que funcionam os produtores culturais e as instituições com que estes se relacionam.

Neste breve trabalho, vamos tratar de cultura como conjunto de práticas e produtos derivados de processos sociais, considerando as manifestações culturais em seu meio material e histórico.

Se estamos falando de contextos sociais, históricos e econômicos específicos, comecemos então por lembrar que a mais recente das crises da cultura internacionais referiu-se exatamente ao modo de considerar os bens culturais da humanidade. As palavras de ordem desta crise foram exceção e diversidade cultural. Vamos a elas.

\section{Exceção e diversidade cultural}

$\mathrm{Na}$ crise da cultura de que falamos estava presente aquele sentido de distinguir, escolher, decidir, julgar como seriam considerados os bens culturais, porque se formulavam questões cujas respostas indicariam direções muito diferentes: "Deveriam os bens culturais ser considerados apenas como mercadorias iguais a outras existentes no mercado, e tratados social e economicamente da mesma maneira?"; ou "Deveriam estes ser considerados como manifestações socialmente diferenciadas e ter um tratamento especial?" Estas questões foram formuladas, diga-se de passagem, em um ambiente no qual havia propostas de colocar os bens culturais (livros, músicas, filmes etc.) como meros itens na pauta internacional de comércio.

Na primeira década do século XXI, o governo norte-americano jogou todo o peso de sua influência para que, em fóruns internacionais, se julgassem os bens culturais da mesma forma que todos os outros bens que eram objeto de negociação entre países, ou seja, da mesma forma que carros, panelas, parafusos ou latas de lixo. Argumentava que, se os bens culturais podem ser comprados e vendidos, como estes outros, então não deveriam ser distinguidos, porque todos teriam o mesmo caráter de mercadoria no comércio internacional e deveriam ser regidos pelas mesmas regras que regem as compras e vendas das outras mercadorias. E que regras seriam essas?

Do ponto de vista norte-americano, deveriam ser as do liberalismo. Os produtores de bens culturais não deveriam ter, por parte dos estados nacionais, nenhum tipo de regalia ou atenção 
especial dos respectivos governos ou sociedades, e deveriam produzir e apresentar suas mercadorias para compra e venda do mesmo modo que outros produtos. Por exemplo, um filme norte-americano não deveria receber nenhum tipo de regalia, incentivo financeiro ou fiscal do governo dos EUA, e deveria não só ter entrada livre em todos os outros mercados nacionais, como ter concorrentes nesses mercados que também não recebessem nada do Estado em que se inserissem. Isso supostamente significaria a igualdade internacional de oportunidades para todos os produtores culturais e a liberdade para circulação das mercadorias que produzissem, sem a "interferência" governamental. Claro, seguindo de modo estrito este ponto de vista, a questão dos bens culturais teria de ser decidida exclusivamente pela Organização Mundial do Comércio.

O ponto de vista oposto, inicialmente defendido pela França e pelo Canadá, era o de que bens culturais, embora tenham também características de mercadoria, não podem ser tratados da mesma maneira que carros, panelas, parafusos ou latas de lixo. Por quê? Porque nesses bens concentram-se elementos importantes para o sentido da vida humana como um todo e as diversas comunidades humanas em suas particularidades próprias.

Além disso, aquela versão de liberalismo norte-americano, embora sustentada por um discurso que propõe igualdades formais, seria consolidadora de desigualdades reais, já que, de fato, a ideia de que todo o mundo tem ou deve ter as mesmas condições para a produção e consumo de bens culturais esbarra com a realidade de que produtores culturais em países que têm mais recursos podem mais. Se determinados países têm um "mercado" maior e mais rico para seus "bens culturais", isto significa maior facilidade para que estes bens sejam financiados e difundidos não somente dentro de suas fronteiras nacionais, mas também exportados. Esta facilidade permite também que o modo de ser e estar no mundo das populações destes países mais privilegiados circule mais amplamente em outros países. Assim, pode ser justificável alguma forma de intervenção que, entre outras coisas, procure tornar menos desiguais as oportunidades de produção e circulação destes "bens", já que a questão da divulgação e reconhecimento das diferentes culturas interfere na política e na economia internacionais. Foi por isso que o ex-presidente francês François Mitterand argumentou no parlamento europeu, em 1995:

A exceção cultural é a ideia de que as obras do espírito não são mercadorias como as outras; é a convicção de que a identidade cultural de nossas nações e o direito de cada povo ao desenvolvimento de sua cultura estão em jogo; é a vontade de defender o pluralismo, a liberdade, para cada país, de não abandonar a outros seus meios de representação, isto é, os meios de se fazer presente a si próprio. (apud GORNAY, 2002, p. 88-89) 
Assim, se os bens culturais estivessem apenas submetidos às hegemonias e predominâncias que marcam as relações comerciais de "mercado", isto geraria uma série de problemas. Claro, problemas não para as nações com maior poder econômico, que poderiam continuar a inundar o mercado de nações menos privilegiadas, com filmes, música, livros que configuram os sentidos dominantes naquelas nações poderosas, deixando de lado outros sentidos que seriam relevantes para comunidades nacionais menos privilegiadas.

Considerando que os empreendimentos culturais mais lucrativos operam em escala de produção, circulação e venda que presume um público de massa para seu financiamento e lucro, então a indústria norte-americano do cinema, por exemplo, já parte de uma base de mais de 200 milhões de potenciais compradores nacionais de ingressos. Compradores de ingresso, claro, que podem ver nesses filmes as suas cidades, sua língua, seus produtos, seu modo de ser e estar no mundo. Em contraste, pode-se condenar a população de um país com cinco milhões de habitantes, e com uma língua e cultura específicas, a assistir filmes e ler livros "estrangeiros", só porque a economia de escala tornaria inviável economicamente fazer filmes que não se financiariam apenas com o público daquele país. Ou seja, pode-se condenar esta população a apenar ver elementos linguísticos e culturais de outras sociedades, sem a possibilidade de reconhecer na tela questões mais especificamente referentes ao seu modo de ser e estar no mundo.

Claro, se quisermos raciocinar de modo mais político, a pergunta poderia ser: - Por que se deveria aumentar a vantagem relativa de certas nações ou grupos de nações no mercado internacional, cujas "mercadorias" (carros, armas, estrutura turística etc.) são divulgadas nestes "bens culturais", em detrimento de outras nações ou grupos de nações, que têm um ônus maior de fazerem conhecidas suas respectivas "mercadorias", porque não têm esta "vantagem relativa"?

Também existia e ainda existe a percepção de que, em relação aos fenômenos culturais, especialmente aos "produtos" que podem ser encaixados neste rótulo (livros, filmes, gravações musicais etc.) havia (e há) um desejo de universalização de normas jurídicas e técnicas para sua produção, circulação, compra e venda, sendo a natureza destas normas decidida em fóruns "globalizados", como a Organização Mundial do Comércio, de acordo com os interesses hegemônicos que pautam estes temas naqueles fóruns.

A classificação dos bens culturais apenas como mercadorias, permitindo um jogo que beneficiaria interesses hegemônicos, afeta, entre outras coisas, as questões de autoidentidade das diversas sociedades humanas. Isto porque interfere na produção e circulação de representações e imagens de um determinado país e de sua população, num momento em que uma das grandes questões da 
circulação de bens culturais e literários é a assimetria nas trocas internacionais, no que diz respeito a bens de cultura (muito mais especialmente no que diz respeito aos que dependam fortemente da língua na qual eles estão estruturados, como é o caso da literatura; nesse caso, deparamo-nos com uma situação concreta: a existência de uma posição dessemelhante entre projetos que estão vinculados a uma determinada língua ou a outras).

Assim, quando se tenta levar para fóruns globalizados a questão da cultura, e transformar os bens culturais em apenas mais um item de comércio, isto significa tentar "congelar" uma situação de fato, transformando-a em uma situação de direito, que beneficia uns em detrimento de outros, criando uma legislação internacional que mantenha a hegemonia dos atuais interesses vigentes. Não admira, portanto, que tenha havido uma forte oposição a isto, primeiramente argumentando que deveria existir uma exceção cultural, contemplando os bens culturais por serem manifestações especiais, oposição que consolidou as bases para a afirmação da diversidade cultural.

Em outubro de 2005, a United Nations Educational, Scientific and Cultural Organization aprovou a Convenção sobre a Proteção e Promoção da Diversidade das Expressões Culturais, documento que reconhece que serviços, bens e atividades culturais possuem "tanto uma natureza econômica quanto cultural, porque veiculam identidades, valores e sentidos, e não devem, portanto, ser tratados como se tivessem somente valor comercial" (UNESCO, 2005).

Além disso, esta Convenção chama a atenção sobre os processos de globalização que têm sido facilitados pelo rápido desenvolvimento de tecnologias de informação e comunicação, gerando, ao mesmo tempo, efeitos positivos e desafios. Como positivo, o documento aponta as condições favoráveis e sem precedentes para a intensificação da interação entre culturas. Aponta também, como desafio à diversidade cultural, os riscos de desequilíbrio entre países ricos e pobres.

Muitos associam diretamente a diversidade cultural às políticas de multiculturalismo vigentes em muitos Estados nacionais no Ocidente. Claro, o respeito às particularidades da cultura do outro, em Estados com populações heterogêneas, tem uma função importante. Permite, entre outras coisas, que não se estigmatizem como "esquisitos" ou "inferiores" certos elementos de culturas minoritárias dentro de um Estado nacional. Em vez disso, o multiculturalismo propõe uma espécie de "política do

2 A expressão refere-se ao famoso ensaio de Charles Taylor: "The Politics of Recognition" (In: ----- et alii. Multuculturalism: Examining the Politics of Recognition. Princeton: Princeton University Press, 1974. p. 25-74.) reconhecimento" ${ }^{\prime 2}$, em que se reivindica a legitimidade de cada comunidade ter sua cultura reconhecida em seus próprios termos.

No entanto, um outro lado do multiculturalismo é a necessidade de definir quem é o outro a ser reconhecido. Esta necessidade pode também levar a uma consolidação de identidades culturais que transforme o movimento social das populações humanas em seu face a face cotidiano (no qual há uma interpenetração 
cultural sempre em movimento) em uma espécie de separação institucionalizada.

De alguma forma, a política do multiculturalismo também é responsável por idealizar identidades e as transformar em homogeneidades que não existem de fato, ou que passam a existir depois de idealizadas e transmitidas como fato. É por isso que Hannerz argumenta que devemos nos preocupar quando o Estado, ainda que com intenções benévolas, propõe a cultura como categoria administrativa, transformando a experiência e a interação, que em comunidades humanas são próprias do encontro cara a cara, em palavras e regras (HANNERZ, 2001).

As políticas de multiculturalismo, se têm um lado positivo de apoiar a diversidade cultural, tornando legítimas as pretensões de grupos sociais minoritários a terem sua cultura respeitada em contextos em que os grupos predominantes poderiam excluí-la ou enquadrá-la como "esquisita" ou "inferior", por outro lado podem também servir para apenas multiplicar indefinidamente as diferenças, ignorando a experiência histórica das sociedades com a interseção de culturas. Se o outro deve permanecer o outro, respeitado, mas separado, sua diferença só vai gerar indiferença naqueles que porventura não pertençam ao âmbito deste outro. Não será mais difícil pensar o que pode unir os homens, num ambiente em que se valoriza o que os divide? Como pensar no que pode ser comum, se a noção de comunidade não vai além de grupos unidos por interesses ou identidades que se alimentam do que se lhes opõe - ou seja, do outro, em relação ao qual se constituem como "diferentes"?

De toda maneira, o modo como os Estado intervêm na cultura é uma questão incontornável da contemporaneidade, questão sobre a qual falaremos a seguir.

\section{Estados nacionais, globalização e cultura}

Começo por dizer algo óbvio, mas nem sempre lembrado: Estados-nações diferentes têm a seu dispor recursos e modos diferentes de inserção de suas perspectivas, interesses e respectivas culturas nos circuitos internacionais.

Estados-nações mais poderosos têm melhores condições para fazerem circular seus bens culturais (literatura, música, artes plásticas etc.) e até gerar categorias "universais" de julgamento a partir desta circulação - categorias que podem levar ao reconhecimento de que apenas ou predominantemente o que corresponde à estrutura destes bens culturais é "belo" ou é "bom".

Nos Estados-nações que não têm o mesmo poder de fogo, surgem estruturas de replicação que internalizam estas categorias do "belo" do "bom" e visam a produzir bens culturais que correspondam a elas. E surge também, principalmente nos Estados-nações pós-coloniais, a necessidade de colocar politicamente a existência de outras estruturas, que - embora não correspondam 
àquele "belo" ou "bom" - também aspiram a serem consideradas belas ou boas, e para isto necessitam da emergência e legitimação de outras categorias de julgamento.

Em alguns contextos, grupos não-nacionais podem querer que sua identidade seja reconhecida e respeitada -por exemplo, escritores "regionais", gaúchos ou nordestinos-; em outros, os mesmos escritores podem não querer marcar o pertencimento a este grupo "menor". Eles podem querer enfatizar seu pertencimento a uma comunidade vista como "maior" ou mais abrangente: por exemplo, marcando sua identidade nacional, em oposição a outros escritores de outros países, que marcam outras identidades nacionais.

Boaventura de Sousa Santos chama o contexto atual de sistema mundial em transição, e diz que este sistema é constituído por três constelações de práticas coletivas: a de práticas interestatais; a de práticas capitalistas globais; a de práticas sociais e culturais transnacionais.

As práticas interestatais corresponderiam ao papel dos estados no sistema mundial moderno como protagonistas da divisão internacional do trabalho no seio da qual se estabelece a hierarquia entre centro, periferia e semiperiferia.

As práticas capitalistas globais seriam aquelas próprias dos agentes econômicos cuja unidade espácio-temporal de atuação real ou potencial é o planeta.

As práticas sociais e culturais transnacionais seriam os fluxos transfronteiriços de pessoas e culturas, de informação e comunicação.

Cada uma destas constelações e práticas seria constituída por: a) um conjunto de instituições que asseguram a sua reprodução, a complementaridade entre elas e a estabilidade das desigualdades que elas produzem; b) uma forma de poder que fornece a lógica das interações e legitima as desigualdades e as hierarquias; c) uma forma de direito que fornece a linguagem das relações intrainstitucionais e o critério da divisão entre práticas permitidas e proibidas; d) um conflito estrutural que condensa as tensões e contradições matriciais das práticas em questão; e) um critério de hierarquização que define o modo como se cristalizam as desigualdades de poder e os conflitos em que eles se traduzem.

Para Boaventura de Sousa Santos, ainda que todas as práticas do sistema mundial em transição estejam envolvidas em todos os modos de produção de globalização, nem todas estão envolvidas em todos eles com a mesma intensidade. (SANTOS, 2002, p. 56-57)

Algumas das práticas culturais transnacionais nasceram no próprio ambiente em que os fenômenos designados como "globalização" ocorrem. Os direitos de nacionalidade e residência em cada um dos países europeus e sul-americanos mudaram em face da criação da União Europeia e do MERCOSUL. As organizações não governamentais (ONGs) com agendas transnacionais, que defendem projetos, políticas e normas universalizantes, como

Niterói, n. 33, p. 33-45, 2. sem. 2012 
3 Para uma narrativa extremamente favorável sobre a história da implantação de regras transnacionais (hoje há um enorme volume de outras narrativas, para explicar porque estas não foram suficientes para evitar crises financeiras internacionais), cf. Drahos and Braithwaite, 2001: "O início deste sistema global ocorreu no colapso do Herstaat Bank na Alemanha e no colapso do banco atacadista americano, o Franklin $\mathrm{Na}-$ tional. Tornou-se claro para os reguladores que tais colapsos implicavam niveis muito mais altos de risco sistêmico, por causa da natureza integrada do sistema financeiro. A resposta dos responsáveis pelos sistemas financeiros nacionais, os diretores dos bancos centrais, foi rápida. Sob os auspícios do G10, os diretores dos bancos centrais daquele grupo de países estabeleceu no fim de 1974 o que agora é conhecido como Basle Comittee on Banking Supervision. A primeira realização do Basle Comittee foi a produção de um conjunto de princípios objetivando desenvolver linhas de supervisão de responsabilidade para um banco estabelecido em mais de uma jurisdição. Uma das características principais do sistema de regulação que o Basle Comittee erigiu é que ele abrange princípios, padrões e linhas mestras que são não-legais em sua natureza. Contudo, apesar disto, muitos padrões que o Basle Comittee estabelece têm sido adotados quase universalmente por bancos que atuam internacionalmente (...). (...) Lentamente, silenciosamente, passo a passo, o Basle Comittee age para coordenar o surgimento de um regime bancário global que opera na base de uma cooperação auto-regulada." (Drahos \& Braithwaite, 2001, p. 114-115.) a World Wild Life, funcionam em escala transnacional. O direito de propriedade intelectual, embora originalmente elaborado em termos nacionais, tem ganhado escala transnacional. Contudo, os termos em que estes direitos são formulados pagam pesado tributo a um certo número de Estados-nações, que investem cada vez mais em órgãos de abrangência global, como a Organização Mundial do Comércio, para fazer com que seus interesses específicos sejam contemplados.

Neste sistema de trocas e transferências desiguais, também no nível cultural se estabelecem agendas em que a cultura hegemônica transforma seus valores e artefatos em "universais", a partir dos quais toda produção cultural diferente da sua passa a ser vista como "local", "regional", "exótica" ou qualquer coisa neste âmbito de sentido. É por isto que Boaventura de Sousa Santos diz que o processo que cria o "global", enquanto posição dominante nas trocas desiguais, é o mesmo que produz o "local", enquanto posição dominada e, portanto, hierarquicamente inferior (SANTOS, p.63).

Já vimos que a Convenção sobre a Proteção e Promoção da Diversidade das Expressões Culturais, de 2005, apontava para "a intensificação da interação entre culturas". De fato, em nossos dias há uma interação muito maior do que nos séculos anteriores, não só porque as tecnologias digitais fornecem meios de conexão nunca antes vistos, mas também porque existem meios de transporte hoje que permitem o deslocamento rápido e seguro de pessoas através do planeta, em uma escala sem precedentes. Claro, se globalização significasse meramente que partes do mundo estão interconectadas, então não haveria nada novo sobre esta assim chamada globalização; ela teria começado há séculos atrás, quando Colombo velejou através do Atlântico, se não antes; a única novidade estaria nos graus de expansão no comércio e transferência de capital, mão de obra, produção, consumo, informação e tecnologia, que poderia ser volumosa o suficiente para resultar em mudança qualitativa (MIYOSHI, 1999, p. 248).

É relevante, contudo, assinalar que a circulação internacional tem graus de movimentação diferente, conforme o que circula. Se prestarmos atenção à atuação do Estado-nação como controlador do fluxo de bens e serviços, dinheiro e pessoas, dentro de suas fronteiras territoriais, veremos que há uma diferença de tratamento dos interesses globalizadores em relação a estes itens.

Em relação ao dinheiro, os patrocinadores da globalização conseguiram um extraordinário sucesso em implantar regras transnacionais que facilitaram a movimentação do capital, e por outro lado tornaram mais difícil regular a especulação³. Já a movimentação de pessoas para trabalhar em outros países encontra hoje maiores dificuldades do que antes da invenção do passaporte.

Claro, sempre se pode, como faz John Tomlinson (1999, p. 4-10), usar os termos conectividade e proximidade como compo- 
nentes incontornáveis da globalização. Proximidade não significa que as distâncias físicas entre os vários lugares de nosso planeta tenham se alterado através dos séculos, mas que experimentamos a distância de um modo diferente daquele que os primeiros colonizadores experimentaram. Hoje, viajando de avião, podemos gastar menos tempo do Rio de Janeiro à Europa do que os portugueses gastaram no passado para ir daquela cidade às Minas Gerais em lombo de animais. Lugares mais distantes tornaram-se acessíveis em tempo mais reduzido, produzindo uma sensação de proximidade que não havia antes. Além disso, as possibilidades de conexão entre pessoas e sociedades vêm-se multiplicando através do desenvolvimento de novas tecnologias eletrônicas e seus derivados.

Por exemplo, minha irmã trabalhou muitos anos no Rio de Janeiro para uma firma cuja sede era nos EUA, mas que mantinha um escritório no Rio conectado digitalmente por banda larga ao Texas, de modo que os trabalhadores daqui podiam em tempo real executar tarefas para e com os seus pares norte-americanos, no desenvolvimento de projetos encomendados à firma nos EUA. Isso seria absolutamente impossível para a geração do meu pai. Na época dele, para trabalhar junto era basicamente necessária a presença de todos simultaneamente em um mesmo espaço físico.

Já minha irmã era parte de uma operação de outsourcing, termo pelo qual se designou, entre outras coisas, a transferência de trabalho (anteriormente realizado no país de origem das empresas) para outros países onde haja mão de obra capacitada para realizá-lo a um custo menor. ${ }^{4}$ Tanto minha irmã como eu, embora tenhamos trabalhado em conexão com outros profissionais que vivem em outros países e se comunicam conosco em línguas que não são a nossa, vivemos basicamente na mesma cidade, o Rio de Janeiro, desde a nossa infância, tirando os períodos de estadia em outros países. De certa maneira, a nossa cidade se globalizou, permitindo que, embora tenhamos permanecido lá, pudéssemos ter uma experiência de conectividade que tornou próximas coisas e pessoas que fisicamente sempre estiveram e continuam distantes fisicamente.

As redes de relações sociais e profissionais também se altera-

4 A proximidade e conectividade de lugares distantes gera também, entre outros problemas, grandes possibilidades de equívocos e malentendidos, razão pela qual empresas que fazem outsourcing usualmente fazem manuais para explicar diferenças culturais entre os hábitos do país sede e os dos países onde ocorre o outsourcing. 
ser inteligível. Há sempre alguma relação entre ações particulares e coletivas que envolve o modo como universidades, centros de pesquisa, laboratórios, editoras, periódicos acadêmicos, agências de fomento à pesquisa, entre outras instâncias, estão implicados nesta conectividade, e o engajamento dos agentes no processo.

No meu caso, me interessam muito diretamente as textualidades digitais, e não apenas aquelas que guardam relação com Gutenberg, ou com o universo do papel. Entre as muitas coisas que eu poderia dizer sobre o assunto, escolho, para terminar, algo que Gutenberg não mudou: publicar um texto, até a vulgarização do meio digital, significava depender de algum editor ou assemelhado, para o processamento da publicação. Também significava a presença de livrarias, nas quais os livros eram expostos e vendidos, e distribuidores, para levarem os livros às livrarias.

A internet alterou este contexto. Hoje, não só os editores mais tradicionais publicam e vendem livros on line, como existe uma série de alternativas que antes não existiam. As livrarias, por outro lado, alteraram seu perfil para sobreviverem, pois, em um ambiente no qual o leitor potencial pode encomendar diretamente seu livro pela internet, o lugar da livraria tradicional ficou em xeque. A alteração mais radical, no entanto, foi a possibilidade de o usuário do meio digital poder publicar seu próprio texto, sem a intervenção de nenhum editor ou assemelhado. No entanto, ainda temos uma série de pontes com a tipografia e o mundo de papel, embora nem sempre tenhamos consciência disso. Por exemplo, ao abrimos nossos softwares de processamento de texto em nossos computadores, não prestamos muita atenção aos tipos de letra que usamos. No entanto, os tipos têm história, e muitos deles são nomeados de acordo com quem os desenhou e produziu no passado: Garamond, de Claude Garamond; Baskerville, de John Baskerville; Bodoni, de Giambattista Bodoni; Caslon, de William Caslon; Gil, de Eric Gill (DUNLAP, 2011).

Ainda, se falamos apenas de livros, há quem diga que a quantidade deles on line rebaixou o padrão de qualidade geral que, antes, pelo menos tinha de passar pelo crivo de alguma editoria, e agora nem isso. Pode-se argumentar, contudo, que hoje está on line também um enorme volume de clássicos e de edições raras a que um público mais amplo jamais teria acesso. E não somente para venda. Como exemplo, aqui no Brasil, quero lembrar o caso da digitalização do acervo de José Mindlin, hoje sob a guarda da Universidade de São Paulo, acervo que foi objeto de um projeto temático financiado pela Fundação de Amparo à Pesquisa do Estado de São Paulo, em 2008.

A proposta do Projeto Temático visava a investigar um modelo de implantação de biblioteca digital na USP que atendesse aos princípios de preservação do acervo da Brasiliana de Mindlin, a maior e mais valiosa coleção de livros sobre o Brasil em mãos particulares no mundo. Evidentemente, seria mais fácil 
a preservação desta coleção com um número menor de leitores manuseando os livros (ou seja, com acesso restrito), mas o espírito do doador era de que houvesse acesso amplo.

A única solução que contemplava os dois lados do problema era a digitalização do acervo, pois assim ele poderia ser consultado por um público amplo, geral e irrestrito, sem que isto prejudicasse a vida útil dos exemplares em papel. Diga-se de passagem, ao realizar a digitalização do acervo da maior Brasiliana do mundo, tornando-a disponível on line na rede mundial de computadores, a equipe do projeto também dotou a USP do mais moderno equipamento existente na época, e serviu como núcleo para capacitação tecnológica de agentes científicos para a execução das diversas operações técnicas necessárias à implementação do projeto.

Acrescente-se que, além de a implantação do projeto ter significado uma contribuição para a preservação do acervo, a colocação on line de seu conteúdo implicou uma economia de recursos futuros para a FAPESP e para as agências brasileiras de financiamento à pesquisa, na medida em que não precisaram mais conceder auxílios a pesquisadores do Estado de São Paulo (ou de outros Estados) para se deslocarem a fim de pesquisar no local, já que todos podem ter acesso ao acervo em qualquer computador ${ }^{5}$, em qualquer lugar. Ou seja, pela conectividade, tornou-se próximo e acessível ao pesquisador e ao público em geral um acervo de livros valioso, ao mesmo tempo em que: 1) pouparam-se recursos de agências de fomento à pesquisa; 2) capacitou-se tecnologicamente uma equipe para projetos futuros; e 3) constituiu-se uma base de equipamentos que pode ser utilizada para outros projetos. Acrescente-se ainda que se trata de uma importantíssima contribuição à presença de conteúdos do Brasil na internet, que poderá ser fundamental para todos os usuários da rede mundial de computadores que se interessam por nosso país.

Assim, neste caso tivemos um bom exemplo de atividades cujo foco comum foi a investigação de um modelo de implantação de uma biblioteca digital que atendesse aos princípios tanto de preservação de acervo importantíssimo para a cultura brasileira, quanto de democratização do acesso e suporte à investigação. $\mathrm{O}$ projeto contemplava uma série de resultados conceitualmente coerentes, desde a elaboração e transmissão de conhecimento sobre bibliotecas digitais, sobre direitos autorais (ele aderiu à $D e-$ claração de Berlim sobre o acesso livre ao conhecimento nas Ciências e Humanidades, de 2003), até a formação de recursos humanos com capacitação tecnológica em processamento digital de ponta.

Contudo, para encerrar nossa exposição, não podemos

5 Na verdade, para ser mais preciso, por questões de direito autoral, a parte do acervo que ainda não está em domínio público não foi colocada ainda on line. 
poderão compreender os princípios pelos quais estas obras podem ser consideradas um conjunto, e incorporadas ao sistema cultural junto com outros conjuntos, de tal forma a serem "preservados", "conhecidos", "transmitidos".

\begin{abstract}
In this article, after presenting some of the perspectives relating to the contemporary association of culture and crisis, we will then consider the issues of Cultural exception (French: exception culturelle), diversity of cultural expressions, national affiliations and globalization, seeking to highlight the plurality of perspectives involved.
\end{abstract}

Keywords: Culture; crisis

\title{
REFERÊNCIAS
}

DRAHOS, Peter and BRAITHWAITE, John. The Globalization of Regulation. The Journal of Political Philosophy: Volume 9, Number 1, 2001, p. 103-128.

DUNLAP, David W.Types With Plenty of Character. http://www. nytimes.com/2011/12/24/arts/design/printing-for-kingdom-empire-republic-review.html?pagewanted $=1 \& \_r=2 \& n l=$ todaysheadlines\&emc $=$ tha2 8

GOURNAY, Bernard. Exception culturelle et mondialization. Paris: Presses de la Fonation Nationale des Sciences Politiques, 2002.

HANNERZ, U. La diversità culturale. Bologna: Il Mulino, 2001.

MIYOSHI, Masao. Globalization and the University. In: JAMESON, F. \& MIYOSHI, Masao, eds. The Cultures of globalization. 3. ed. Durham: Duke University Press, 1999. p. 371-384.

SANTOS, Boaventura de Sousa. Globalização cultural ou cultura global? In: ---. A globalização e as Ciências Sociais. 2. ed. São Paulo: Cortez, 2002.

TAYLOR, Charles. The Politics of Recognition. In: ----- et alii. Multuculturalism: Examining the Politics of Recognition. Princeton: Princeton University Press, 1974. P. 25-74.

TOMLINSON, John. Globalization and Culture. Cambridge: Politry Press, 1999.

UNESCO. Convention on the Protection and Promotion of the Diversity of Cultural Expressions 2005. In: http://portal.unesco.org/en/ev.phpURL_ID=31038\&URL_DO=DO_TOPIC\&URL_SECTION=201.html

WEIL, E. Essais et conférences. Paris: Vrin, 1991. t. II. 